\title{
THE
}

\section{Identification of a putative man-made object from an underwater crash site using CAD model superimposition}

Jay Vincelli

Fatih Calakli

Michael Stone

Graham E. Forrester

University of Rhode Island, gforrester@uri.edu

Timothy Mellon

See next page for additional authors

Follow this and additional works at: https://digitalcommons.uri.edu/nrs_facpubs

The University of Rhode Island Faculty have made this article openly available.

Please let us know how Open Access to this research benefits you.

This is a pre-publication author manuscript of the final, published article.

Terms of Use

This article is made available under the terms and conditions applicable towards Open Access Policy Articles, as set forth in our Terms of Use.

\section{Citation/Publisher Attribution}

Vincelli J, Calakli F, Stone M, Forrester G, Mellon T, Jarrell J. Identification of a putative man-made object from an underwater crash site using CAD model superimposition. Forensic Sci Int 2018;285:129-34.

This Article is brought to you for free and open access by the Natural Resources Science at DigitalCommons@URI. It has been accepted for inclusion in Natural Resources Science Faculty Publications by an authorized administrator of DigitalCommons@URI. For more information, please contact digitalcommons-group@uri.edu. 
Authors

Jay Vincelli, Fatih Calakli, Michael Stone, Graham E. Forrester, Timothy Mellon, and John Jarrell

This article is available at DigitalCommons@URI: https://digitalcommons.uri.edu/nrs_facpubs/180 


\section{Identification of a putative man-made object from an underwater crash site using CAD model}

2 superimposition

3 A comparison of unique features on an underwater object are compared to the features of a known object

4 modeled in CAD to assess its likelihood as being a component from a downed plane at the suspected

5 incident scene.

6 Jay M. Vincellia , jvincelli@ materialsscience.org

$7 \quad$ Fatih Calaklia, ${ }^{\mathrm{a},}$, fatih_calakli@brown.edu

$8 \quad$ Michael Stone ${ }^{\mathrm{a}, \mathrm{c}}$, sstone@ $@$ materialsscience.org

9 Graham E. Forrester ${ }^{c}$, gforrester@uri.edu

10 Timothy D. Mellon, panam.captain@yahoo.com

11 John D. Jarrell ${ }^{\mathrm{a}, \mathrm{b}}$, johnjarrell@ materialsscience.org

12

13 a Materials Science Associates, 315 Commerce Park Rd, Unit 1, North Kingstown, RI 02893

$14 \quad$ b Brown University, 182 Hope St, Providence, RI 02912

$15 \quad{ }^{\mathrm{c}}$ University of Rhode Island, Dept. of Natural Resources Science, Kingston, RI 02881

16

17 Keywords: Vehicle accident; video analysis; Amelia Earhart; aircraft

19 Abstract

In order to identify an object in video, a comparison with an exemplar object is typically needed.

21 In this paper, we discuss the methodology used to identify an object detected in underwater video that was

22 recorded during an investigation into Amelia Earhart's purported crash site. A computer aided design

23 (CAD) model of the suspected aircraft component was created based on measurements made from

24 orthogonally rectified images of a reference aircraft, and validated against historical photographs of the

25 subject aircraft prior to the crash. The CAD model was then superimposed on the underwater video, and

26 specific features on the object were geometrically compared between the CAD model and the video. This 
27 geometrical comparison was used to assess the goodness of fit between the purported object and the 28 object identified in the underwater video. 


\section{Introduction}

Finding and identifying pieces of manmade wreckage in underwater environments can be challenging. Many types of information must be taken into consideration when identifying objects, such

32 as texture, pattern, and color differences. The size and dimensions of objects are also critical and, unless

33 the object is retrieved, must be derived from scaling information plus relative and absolute position. There 34 are many different methods to survey and document artifacts with a wide range of ease and accuracy. [1].

35 Cost and availability are major determining factors when choosing the best way to carry out a survey.

36 Depending on the depth and location, methods can range from side scan sonar to having a diver on site to

37 perform running distance based measurements (Barkai and Kahanov 2007; Telem and Filin 2013).

38 Affordable precise digital cameras are widening the relevancy of photogrammetry in many disciplines.

39 Image based analysis can significantly cut down the man hours needed to identify objects compared to

40 traditional hands-on approaches [4]. Many image based reconstruction methods, based on

41 photogrammetry and geometric principles are available. Stereo cameras can be very effective but require

42 precise calibration and complexity that is too costly for many applications [5]. Approaches for monocular

43 cameras include structure from motion (SfM) [6], projection of structured light [7], and depth from

44 defocus [8]. These methods often require high quality recording and very structured illumination. [9].

45 Underwater photogrammetry provides an efficient and nondestructive mechanism for sampling

environments with limited accessibility. In the absence of enough information to create a dense

47 reconstruction of an object, geometric comparisons can be sufficient to identify objects.

In this retrospective analysis, we were provided with video footage from which we were tasked with identifying any pieces of wreckage and verifying their connection to a wrecked aircraft. The video was taken with a monocular camera on a remote controlled underwater vehicle (ROV). The site was located

51 on a Pacific atoll at 200-300 m depth and so, because of its remoteness, there was no opportunity to return

52 at a later date to take better or closer video of objects identified after filming. As a result, a different, off-

53 site approach for identification of objects in the video was needed. Man-made objects would likely be 54 coated with biologically derived accretions, possibly also with sediment, so analyzing their size and shape 
55 and matching them with known objects is a key first step toward identification. This paper focuses on a

56 method to use features on a man-made object to compare it to both historical photographs as well as an

57 exemplar specimen for identification. Photos of the exemplar specimen were adjusted into an

58 orthographic view. The features were then quantitatively compared to the object of interest and also to

59 historical photos of the aircraft taken prior to the crash.

60 In our previous publication on the same subject matter, we detailed our methodology for 61 superimposing CAD models of landing gear on underwater video [10]. In that case study, a man-made 62 rope was visible adjacent to two pieces of purported landing gear. The two CAD model overlays allowed 63 for independent measurements of the diameter of the reference rope, which showed that the rope 64 statistically had the same diameter and that the rope had an appropriate diameter for aircraft tie-down 65 rope. This indicated that both of the objects seen in the video were of the correct scale and general shape 66 of the landing gear on the wrecked aircraft. However, a goodness of fit of the overlays could not be made

67 due to the geometry of the components. In the present analysis, the repeated rivet patterns provide a 68 unique opportunity to allow a goodness of fit calculation to be performed on a new object located at the 69 same site.

\subsection{Background}

In this case study, we describe using the superimposition of CAD models using underwater video as

72 source data to assess the geometry of objects purported to be from the July 2, 1937 crash site of Amelia

73 Earhart's lost airplane, a Lockheed Electra Model 10E, construction number 1055, off of the island of

74 Nikumaroro in the western Pacific Ocean. This airplane has an overall length of approximately $11.8 \mathrm{~m}$, a

75 wingspan of $16.8 \mathrm{~m}$, and a height of $3.1 \mathrm{~m}$ (Figure 1). The outer skin of the aircraft was attached using 76 rivets, and a section of rivets along the window slide rail appeared to match the objects seen in the 77 underwater video. 


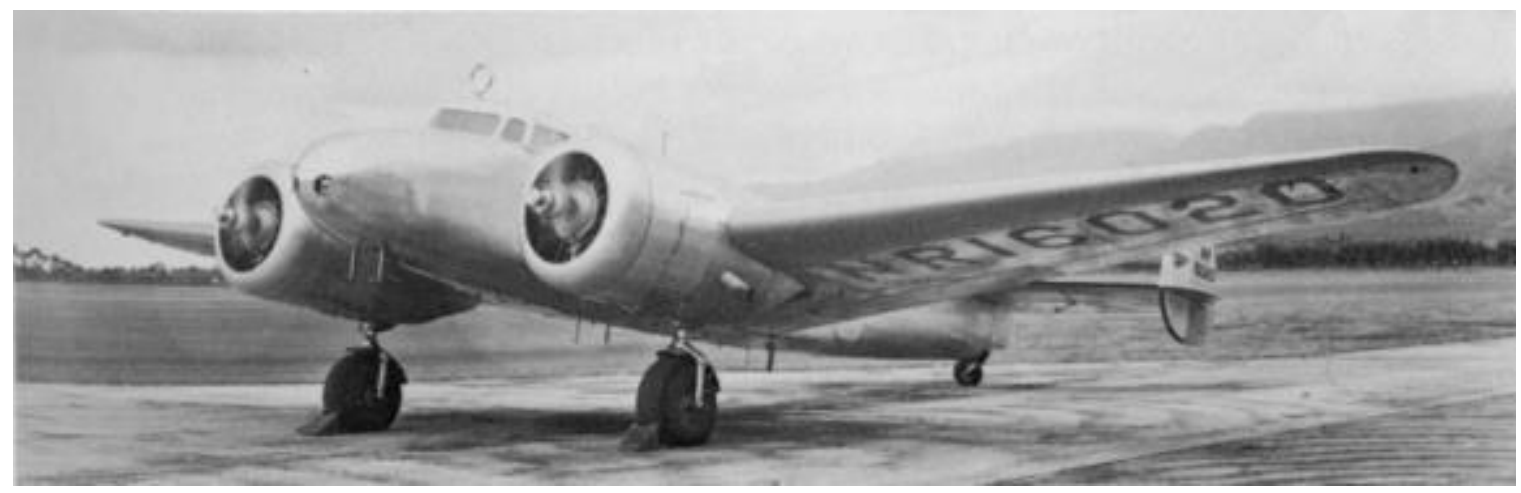

Figure 1: Amelia Earhart's Lockheed Electra Model 10E aircraft. Scanned from Lockheed Aircraft since 1913, by René Francillon. Photo credit USAF.

We received the video for analysis retrospectively and we were tasked with extracting as much information as possible from the video footage itself. During an internal review of the video, two objects were identified which resembled a series of rivets. Rivet patterns covering the aircraft were reviewed and the closest resemblance was the rivets located at the window slide rail. Due to the remoteness of the crash site and difficulty involved in safely retrieving the objects, the objective of this study was to assess the geometry of the purported airplane component to determine whether additional investigation of these objects, such as retrieval, is merited.

\section{Methodology}

Using the provided video, we identified two potentially man-made objects, shown in Figure 2. The top object contains a series of repeating, staggered features on a rectangular or cylindrical base. A second object, perpendicular to the first, contains two long, parallel edges. The left side of the second object contains a series of repeating, staggered features, similar to those on the first object. These objects were investigated further because they presented features that bore a resemblance to a rivet pattern seen on the aircraft in Figure 3, and they were located in the suspected crash site. 


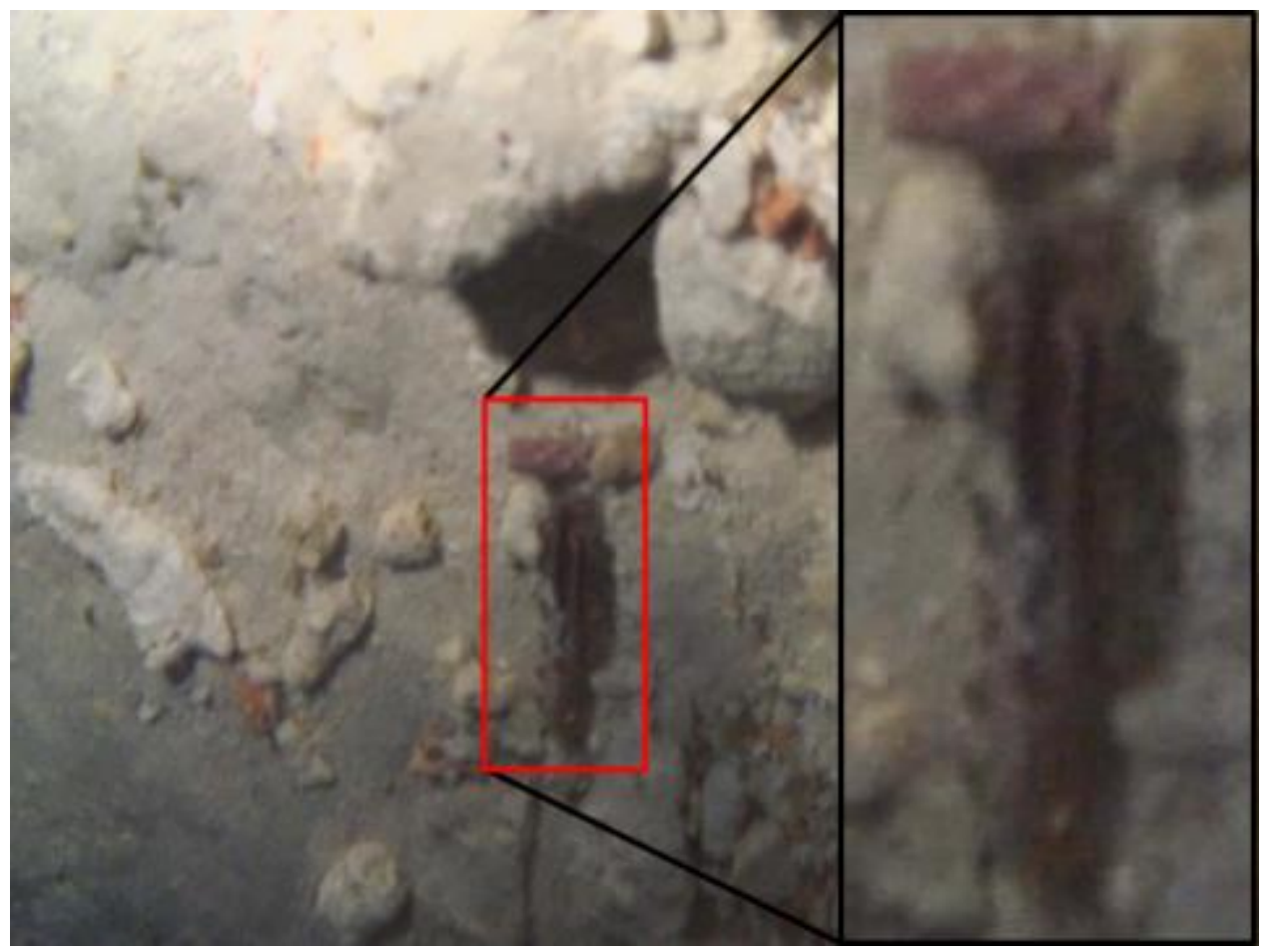

$98 \quad$ Figure 2: An object was identified in the suspected underwater crash site.

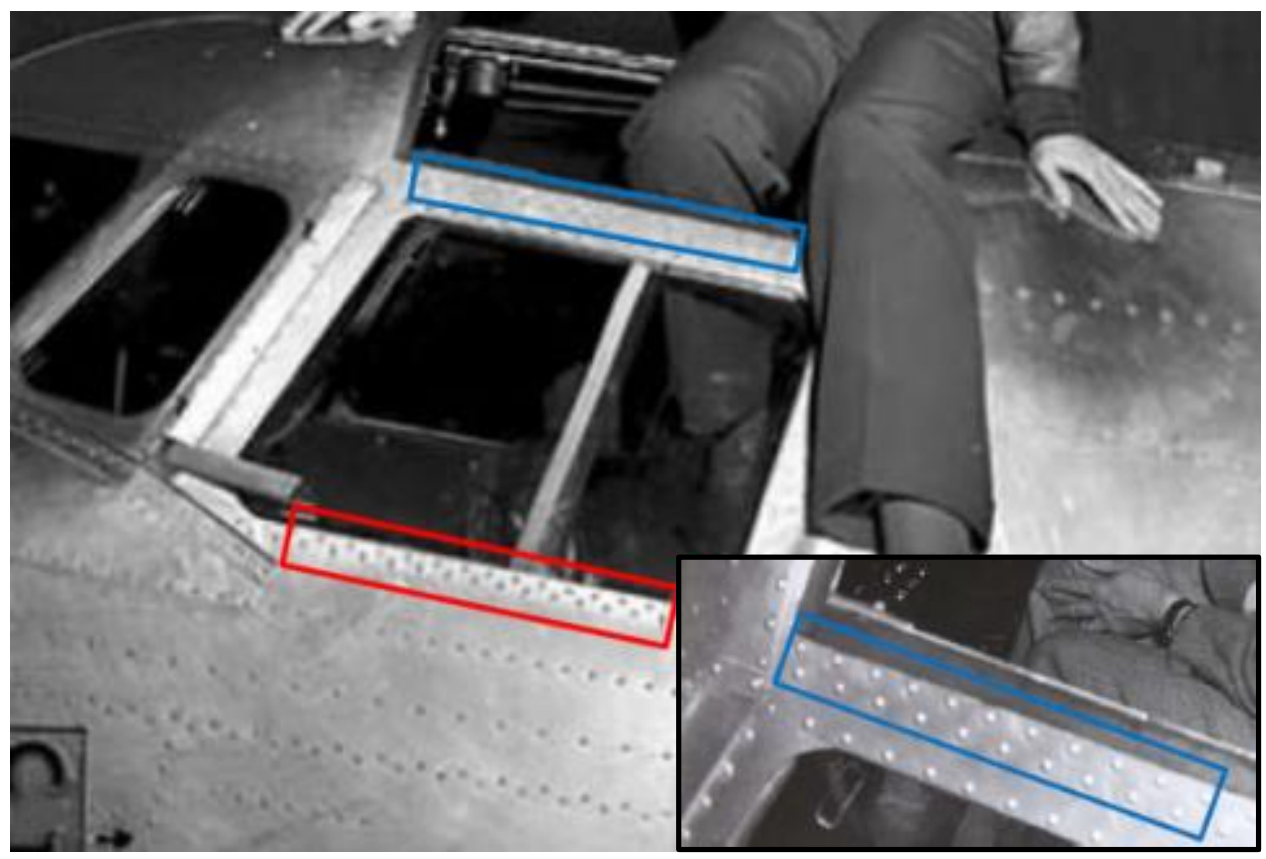

Figure 3: A photograph illustrating a similar pattern of rivets on the aircraft was taken prior to the crash.

We first found historical photos of the aircraft from which the potential piece of wreckage is believed to have originated. Historical photographs of the aircraft were reviewed to identify possible matches to 
the rivet pattern seen in the purported wreckage. The most visually similar parallel features and rivet

104 patterns were located at the window slide rail (red, Figure 3 and Figure 4) and below the hatch (blue,

105 Figure 3).

An aircraft of the same make and model as the one at the potential crash site was used for 107 measurement of the identified rivet pattern, using photographs supplied by the owner of the aircraft. The 108 window slide rail of the intact aircraft contained parallel features, and rivets (Figure 4) that were similar 109 to those seen in the wreckage image (Figure 2) and the historical aircraft (Figure 2).

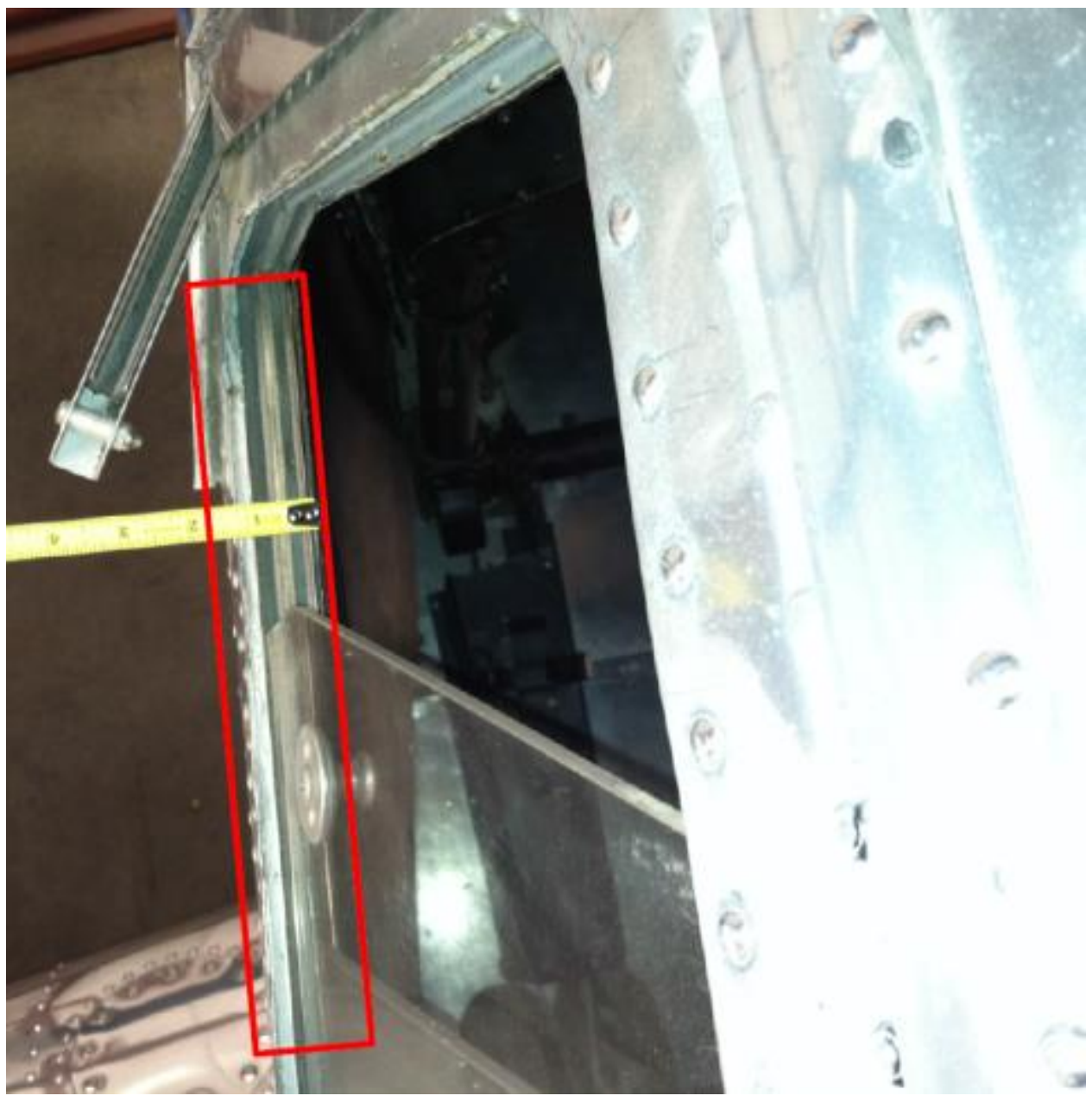

111 Figure 4: Parallel rails constrain the side window and allow it to slide.

A yard stick was placed in the field of view of each photograph of the intact aircraft (Figure 5). In order to take more accurate measurements from the photograph of the window slide rail, an orthographic 
114 transformation of the angled photograph was performed using MATLAB in order to view the window

115 from a perpendicular view (Figure 6). Orthographic projections preserve both distances and angles, and

116 there is no distortion of shape for two-dimensional transformations [11]. The yard stick, having a known

117 length, width, and shape was used as a reference to perform the transformation, with the assumption that

118 the outer face of the window slide rail and yard stick was parallel. The transformed view is orthographic

119 for all features contained in the same plane as the yard stick. The transformed image can be used to

120 measure objects contained in the same geometric plane, such as the rivets on the outside of the slide rail.

121 After the transformation, it is seen that the rectangular geometry and uniform spacing of the yardstick is

122 preserved (Figure 6).

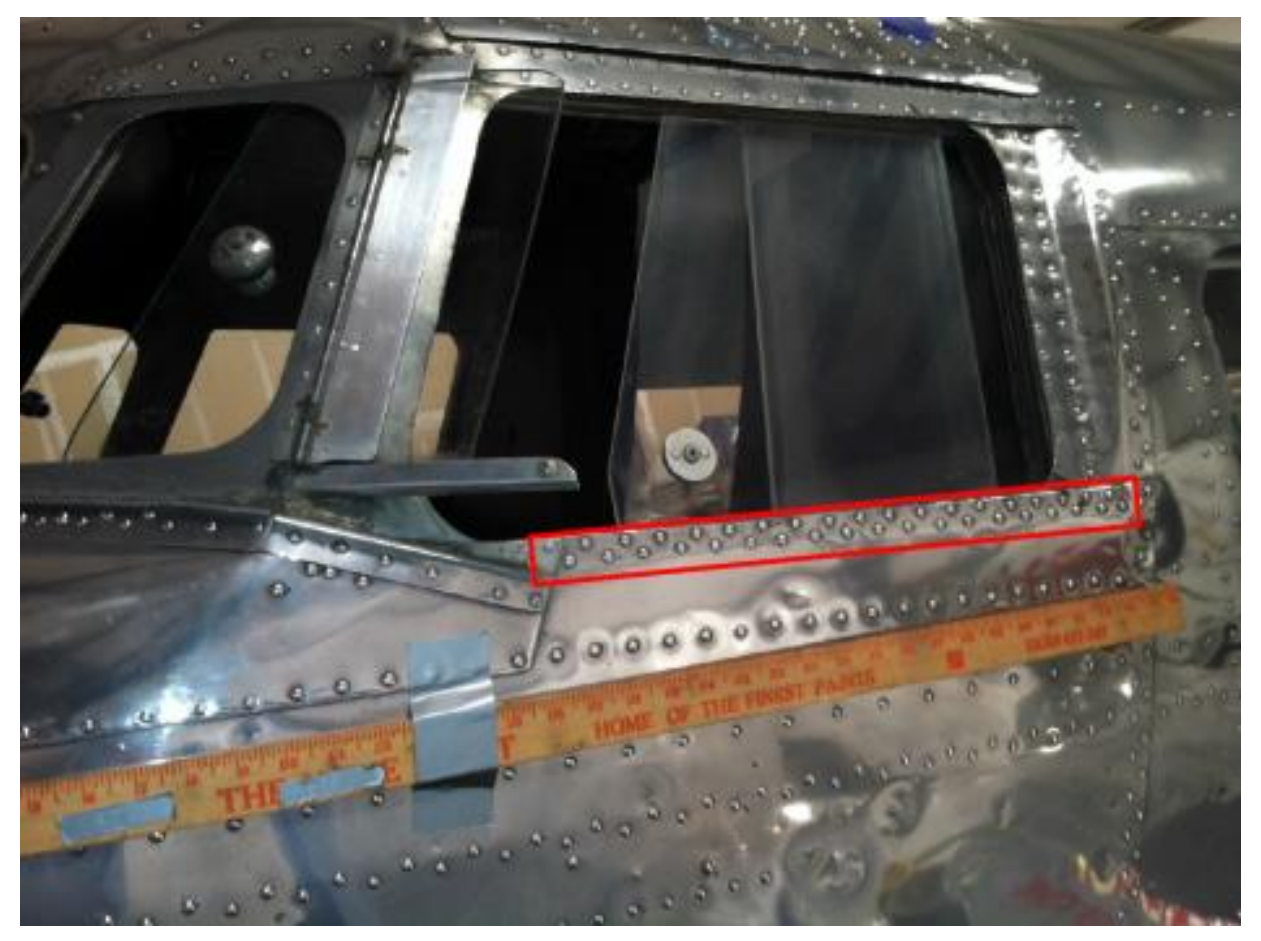

124 Figure 5: The reference aircraft photograph was not taken perpendicular to the yard stick or rivets. 


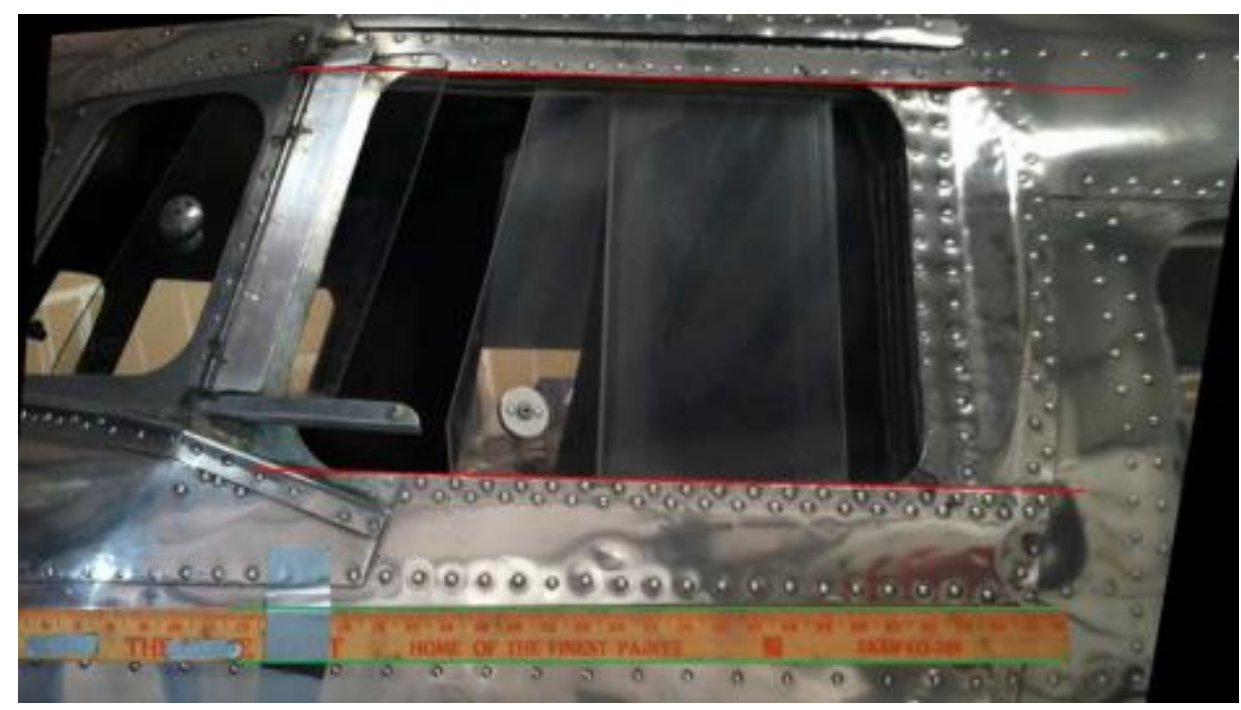

126 Figure 6: The photograph of the reference aircraft was transformed to a perpendicular, orthogonal view.

A 3D CAD model of the window rail was created using measurements taken from the transformed image (Figure 6) and another photograph of the window slide rail (Figure 4). A rivet diameter of $8 \mathrm{~mm}$ 129 was specified. The fits were visually verified with overlays on photos of the intact aircraft and historical 130 photos of the subject historical aircraft (Figure 7). 

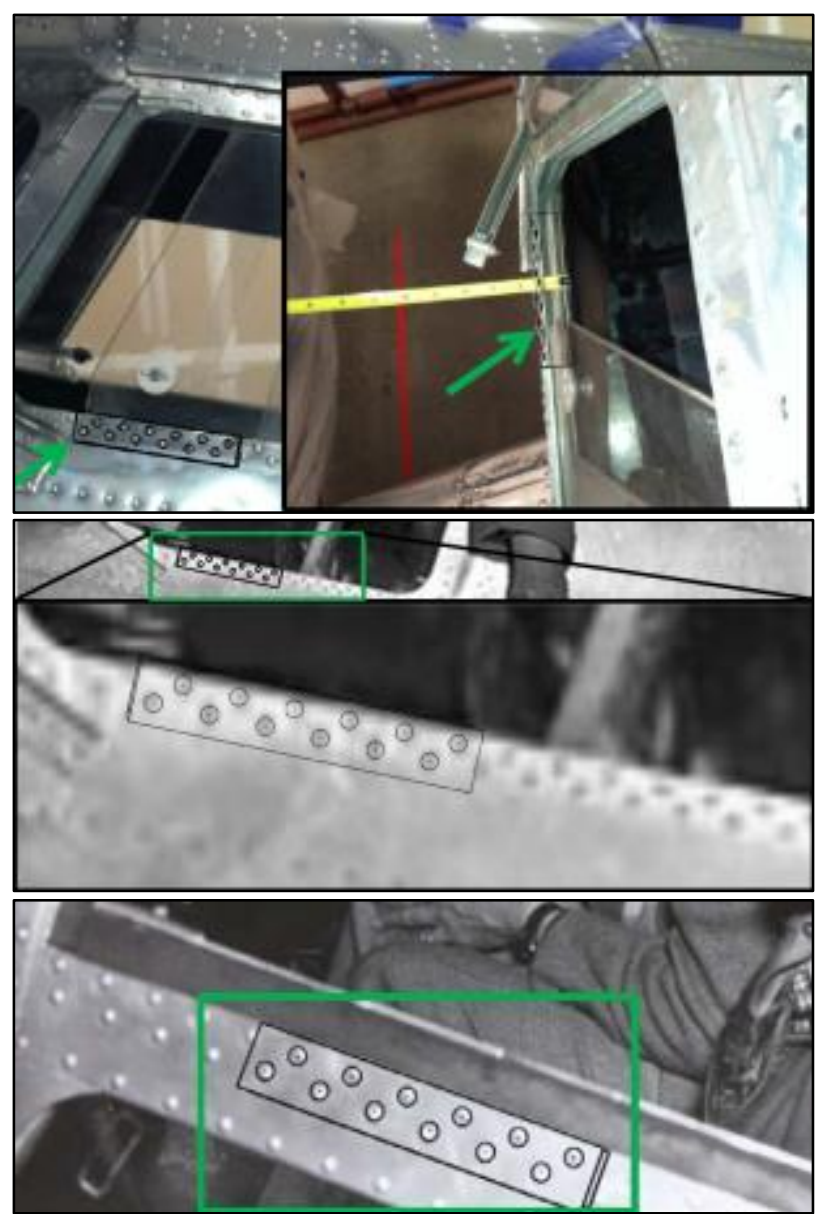

Figure 7: The CAD model was overlaid on the reference aircraft (top) and on historical photos of the crashed aircraft (middle and bottom).

Other sections of rivets seen in the historical photographs the plane, such as those seen in front of the roof hatch and behind the side window, were not good fits for the CAD model. However, another section of rivets, located below the roof hatch in the aircraft (bottom, Figure 7), shared the same size and spacing as the series of rivets below the side window.

For the underwater objects, the estimated center of the purported rivets on the top object, along with

141 the parallel features on the bottom object, were drawn on a de-interlaced still frame from the video of the 142 wreckage where visually identifiable centers could be ascertained. The CAD model of the purported 143 objects was then overlaid in a perspective view onto the original, still frame, obtaining the best visual fit, 144 similar to what was performed in Figure 7 with the historical photograph overlays. Separately, to reduce 145 observer bias, the centers of the purported rivets were visually identified and marked on the image. The 
147 fit (Figure 8).

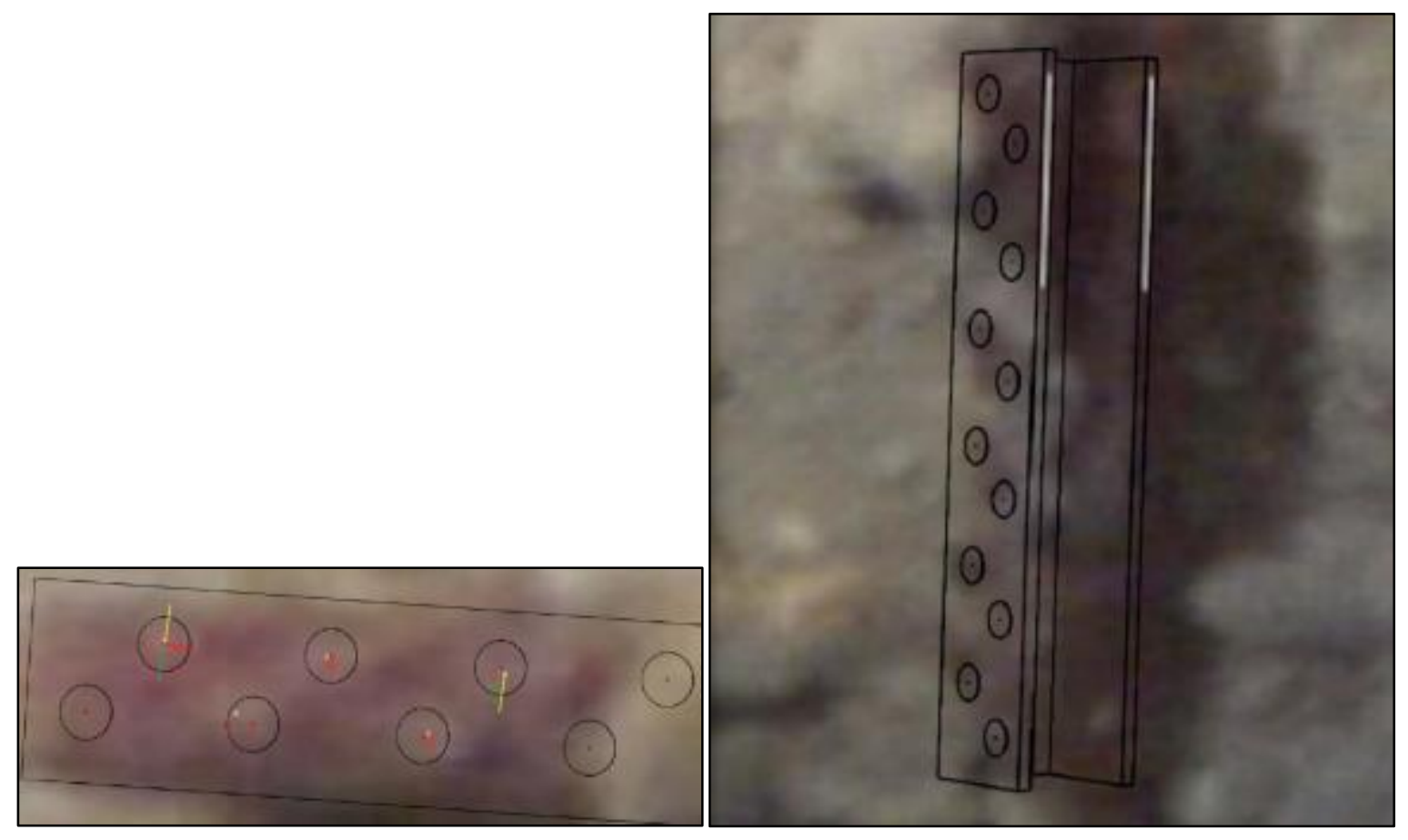

Figure 8: The CAD model of the window slide rail was overlaid onto marked-up images from the wreckage video.

\section{Theory/Calculation}

In order to provide a quantitative measurement of the misalignment error of individual rivets, the distance between each $\mathrm{CAD}$ rivet and the corresponding center of each purported rivet was measured within Solidworks. As a measure of the overall scaling error, a worst-case measurement was taken, which used the farthest-spaced CAD rivets and the farthest-spaced purported rivets as references.

By comparing the center of the CAD model rivets to the centers of the purported rivets in the wreckage image, the level of fit can be defined as follows:

Center of the staggered shapes perfectly align with the centers of the rivets $=$ Perfect fit

Center of the staggered shapes aligns with the edge (radius) of the rivets $=$ Limit of fitting 
160

161

162

163

164
Center of the staggered shapes is outside the radius of the rivets $=$ Not a fit

Numerically,

$$
\text { Fit }=100 \%-100 * \frac{\sum_{k=1}^{n} \text { Distance from center } \text { point }_{k}}{\sum_{k=1}^{n} \text { Radius of rivet }_{k}}
$$

With the radius of the rivet used as the reference, the degree of fit can be expressed as a percentage numerically as:

$$
\text { Perfect fit }=100 \%
$$

Limit of fitting $=0 \%$

Not a fit $<0 \%$

Therefore, there is a fit if the value is between $0 \%$ and $100 \%$, and there is not a fit if the value is negative.

\section{Results}

When the CAD model is overlaid on the image of the wreckage, the centers of the rivets do not perfectly align. The distance between these centers was measured. The average error, or mean of these distances, was $1.3 \mathrm{~mm}$ with an arithmetic standard deviation of $1.1 \mathrm{~mm}(\mathrm{~N}=8)$. The distance between the centers of the corresponding, farthest-spaced CAD model rivets measured $52.6 \mathrm{~mm}$. The distance between the centers of the farthest-spaced purported rivets in the wreckage image measured $53.3 \mathrm{~mm}$. The difference between these measurements gives an overall scaling error of $0.7 \mathrm{~mm}$.

Every measured point on the image from the ROV video is located within the radius of the rivets, and using the collected data, there is an $84 \%$ fit between the rivets and the centers of the staggered objects seen in the video. 

the farthest-spaced rivets to measure the error between the image from the ROV video and the CAD 184 model, the error is $1.3 \%$, or conversely, has a fit of $98.7 \%$ using this metric:

$$
\frac{\text { Video Image Distance }-C A D \text { model distance }}{C A D \text { model distance }} * 100
$$
vertical object in the rover image to within $3.18 \mathrm{~mm}$, the approximate thickness of the sheet metal, establishing a second correspondence between the CAD model and the objects on the sea floor. Furthermore, there are additional repeating, staggered features toward the bottom of this vertical object, 191 but the vertical object appears nonuniformly bent. Therefore, it was not useful to perform a numerical 192 analysis of this section of the object.

\section{Discussion}

The approach we used was designed to mitigate any bias or compounded errors, and so provides a powerful way to assess the match between objects at a crash site and known reference objects. Each rivet 197 pattern was measured independently of one another. The CAD models of the rivet patterns from each 198 photograph were also built individually in SolidWorks. The CAD models were visually overlaid onto the 199 ROV image, and an assessment of the goodness of fit was made using the position of the center of rivets. 200 We also calculated a worst case fit from the rivets with the largest discrepancy between the ROV video 201 and CAD model. This gave us an acceptably low percentage error of $1.3 \%$.

202 It is important to keep in mind that a low error simply means that the selected features of the 203 geometry have little difference between the object in the image and the CAD model. An alternative 204 explanation for the origin of the object is that it is naturally made. It was investigated whether this object 
is a skeletal fragment of a hard coral (order Scleractinia) or a soft coral (subclass Octocorallia, also known

206 as Alcyonaria). These are very diverse groups that are represented by many species in the shallow coral

207 reefs that grow in shallow waters above the study area [12-15]. Some species grow as tubular colonies, 208 either branched or unbranched. They have wood-like or calcareous (limestone) skeletons and, when 209 colonies die their skeletons are frequently broken by storms so that tubular skeletal fragments are likely to 210 be found amongst reef debris fields and be washed into deeper water. Branch fragments vary widely in 211 potential size, and the range of possible sizes spans the estimated size of the unknown object. Skeletal 212 fragments could also plausibly match the unknown object in color, because some Octocorallia can have 213 pink or red colonies whose color would persist for a while after death. Alternatively, the white skeletons 214 of Scleractinians may become pink after death if colonized by crustose coralline algae. Most importantly, 215 colonies have polyps, each of which creates a small bump on the branch, and polyps are sometimes found 216 in alternating rows, like those on the unknown object.

217 Ideally, one or more skeletal fragments of known identity would be compared geometrically to the 218 unknown object using the same method we describe for the window slide rail. We screened shallow-water 219 ROV video from the site and confirm that members of both taxonomic groups (Scleractinia and 220 Octocorallia) with the appropriate branching growth form were present in the area (Figure 9 and Figure 221 10, respectively). Defining specific objects for analysis would, however, require either a return trip to the 222 site to retrieve fragments, or identifying candidates to species from the ROV video, neither of which was 223 possible. 


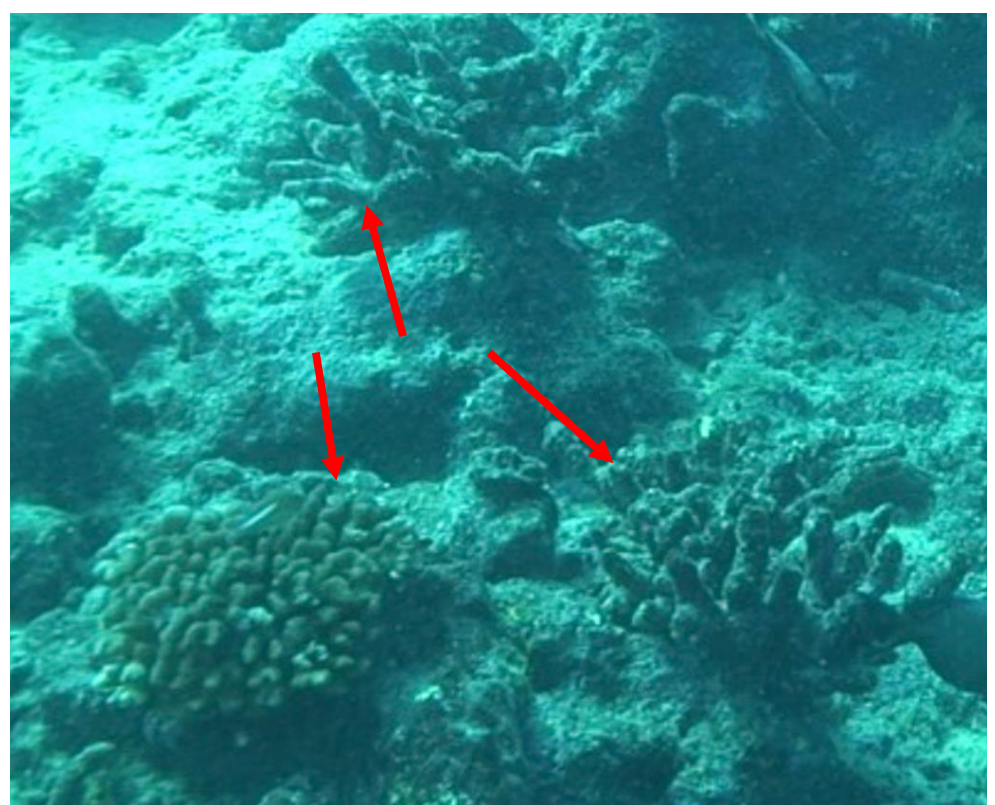

225 Figure 9: Still image from video recorded in shallow waters near the purported wreckage site illustrating

226 hard coral, order Scleractinia.

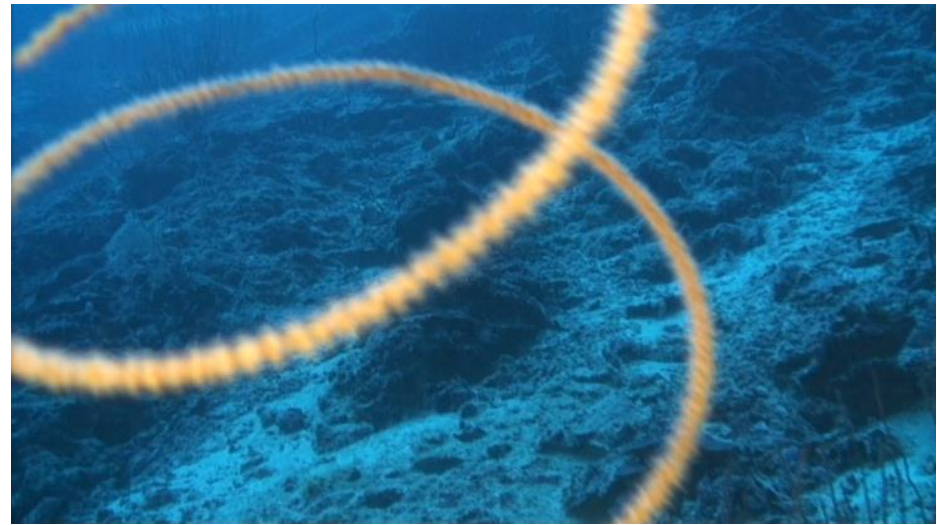

228 Figure 10: Still image from video recorded in shallow waters near the purported wreckage site 229 illustrating soft coral, subclass Octocorallia.

In principle, however, it would be best to obtain examples of several plausible reference objects, 231 whether man made or natural, for comparison with an unknown object identified during a search. In our case study, the ROV search was focused on locating a specific aircraft, which provided a rationale for 233 selecting the chosen aircraft model for comparison. In other search contexts, it might be valuable to apply our method to multiple man-made objects (e.g. riveted fittings from multiple known aircraft models) so 
that the relative goodness of fit of the unknown to a set of plausible reference objects could be judged. In this way, some candidate matches could be excluded, and the search focused by a process of elimination. underwater searches. The man-made objects we were searching for have been exposed for nearly a century. Even with the degradations, silt, and natural growth around it we were able to successfully employ this approach to verify that the unknown objects were a close geometric match to the window slide rail on the lost aircraft that was the subject of the search. The same approach will be of most value in other applications where there is some pre-existing documentation of the potential identity of the unknown objects, so that a small set of plausible alternative reference objects can be specified. complete model of the object to aid in determining the true position of surface features. Better quality video could help alleviate some of the blur and improve the accuracy of points.

\section{Conclusion}

An object in the submarine video was identified as potentially being the window slide rail of a Lockheed Electra Model 10E aircraft. A CAD model of the slide rail was created from measurements taken from a reference aircraft, was overlaid on a still image of the video and goodness of fit measurements were performed.

The rivets of the CAD model taken from the reference aircraft's side window slide rail aligned with objects seen in the rover image with an $84 \%$ fit.

This series of rivets also fit the series of rivets located below the cockpit roof hatch on the historical photographs of the wrecked aircraft. This pattern of rivets did not fit the series of rivets in front of the cockpit roof hatch or behind the side window as seen in historical photographs (Figure 3:). A worst-case measurement comparing the distance between the farthest-spaced rivets had a fit of $98 \%$. The parallel edges in the rover image aligned within the width of the rails of the CAD model. 
261 lost airplane and an object observed only from underwater video filmed in an area of very limited access.

262 From the video we extracted a still frame of a potential man-made object. The object was inspected and 263 the patterns present on the surface were matched to those found on an historical photograph of the 264 aircraft. The same pattern was independently compared to the patterns on a photograph of an extant 265 exemplar aircraft with a worst-case goodness of fit of $98.7 \%$. Videos of the shallow waters surrounding 266 the purported wreckage were reviewed by a marine biologist to assess the likelihood of a natural origin of 267 the object. Soft and hard corals were identified, but none were identified to have exhibited a similar 268 pattern to the subject object. Based on the available data, it is more likely than not within a reasonable 269 degree of scientific certainty that the object is from a Lockheed Electra Model 10E. The methods 270 described herein provide a valuable method to identify unknown objects by comparing their size and 271 shape to that of known reference. 


\section{References}

274 [1] G. Telem, S. Filin, Photogrammetric modeling of underwater environments, ISPRS J. Photogramm. Remote Sens. 65 (2010) 433-444.

276 [2] G. Telem, S. Filin, Photogrammetric modeling of the relative orientation in underwater

277

278

279

280

281

282

283

284

285

286

287

288

289

290

291

292

environments, ISPRS J. Photogramm. Remote Sens. 86 (2013) 150-156.

doi:10.1016/j.isprsjprs.2013.10.001.

[3] O. Barkai, Y. Kahanov, The Tantura F Shipwreck, Israel, Int. J. Naut. Archaeol. 36 (2007) 21-31. doi:10.1111/j.1095-9270.2006.00114.x.

[4] M. Canciani, P. Gambogi, F.-G. Romano, G. Cannata, P. Drap, low cost digital photogrammetry for underwater archaeological Site survey and artifact isertion. The case study of the dolia Wreck in secche della meloria-livorno-italia, ISPRS Work. Vis. Tec. Digit. Archit. Archaeol. Arch. (2003) ?

[5] C. Wöhler, P. d'Angelo, L. Krüger, A. Kuhl, H.-M. Groß, Monocular 3D scene reconstruction at absolute scale, ISPRS J. Photogramm. Remote Sens. 64 (2009) 529-540. doi:10.1016/j.isprsjprs.2009.03.004.

[6] O. Faugeras, Three-dimensional Computer Vision: A Geometric Viewpoint, MIT Press, 1993.

[7] J. Batlle, E. Mouaddib, J. Salvi, Recent progress in coded structured light as a technique to solve the correspondence problem, Pattern Recognit. 31 (1998) 963-982. doi:10.1016/S00313203(97)00074-5.

[8] Y.Y. Schechner, N. Kiryati, Depth from Defocus vs. Stereo: How Different Really Are They?, Int. J. Comput. Vis. 39 (2000) 141-162. doi:10.1023/A:1008175127327.

[9] P. D’Angelo, C. Wöhler, Image-based 3D surface reconstruction by combination of photometric, geometric, and real-aperture methods, ISPRS J. Photogramm. Remote Sens. 63 (2008) 297-321. doi:10.1016/j.isprsjprs.2007.09.005. 
[10] J.M. Vincelli, F. Calakli, M.A. Stone, G.E. Forrester, T. Mellon, J.D. Jarrell, Characterizing a Debris Field Using Digital Mosaicking and CAD Model Superimposition from Underwater Video, Photogramm. Eng. Remote Sens. 82 (2016) 223-232. doi:10.14358/PERS.82.3.223.

[11] M. Shah, K. Rakesh, Video Registration, Springer Science \& Business Media, 2003.

[12] J.E. Maragos, A.M. Friedlander, S. Godwin, C. Musburger, R. Tsuda, E. Flint, O. Pantos, P. Ayotte, E. Sala, S. Sandin, S. McTee, D. Siciliano, D. Obura, US coral reefs in the Line and Phoenix Islands, central Pacific Ocean: status, threats and significance, Coral Reefs USA. (2008) 643-654. doi:10.1007/978-1-4020-6847-8_16.

[13] D. Obura, Coral reef structure and zonation of the Phoenix Islands, Atoll Res. Bull. (2011) 63-82. doi:10.5479/si.00775630.589.63.

[14] D. Obura, S. Mangubhai, Coral mortality associated with thermal fluctuations in the Phoenix Islands, 2002-2005, Coral Reefs. 30 (2011) 607-619. doi:10.1007/s00338-011-0741-7.

[15] S.A. Sandin, J.E. Smith, E.E. DeMartini, E.A. Dinsdale, S.D. Donner, A.M. Friedlander, T. Konotchick, M. Malay, J.E. Maragos, D. Obura, O. Pantos, G. Paulay, M. Richie, F. Rohwer, R.E. Schroeder, S. Walsh, J.B.C. Jackson, N. Knowlton, E. Sala, Baselines and degradation of coral reefs in the Northern Line Islands, PLoS One. 3 (2008). doi:10.1371/journal.pone.0001548. 